\title{
Contaminación moral
}

\author{
POr FRANCISCO BELDA, S. J.
}

El problema de la contaminación ha conseguido una gran actuam lidad en los últimos tiempos. La Conferencia de Estocolmo y las medidas que han empezado a tomarse en muchos países, incluido el nuestro, son pruebas de la preocupación que despierta en amplios círculos un cierto empeoramiento en las condiciones de vida. Durante bastantes años, la preocupación de los países desarrollados ha sido la de producir más cosas. Ahora comenzamos a caer en la cuenta de que no siempre el tener más cosas significa vivir mejor.

En las grandes áreas urbanas y en las zonas industriales, el aire empieza a hacerse irrespirable, porque dicen que tiene demasiado azufre. El agua sabe a cloro, porque se ha vuelto tan sucia que, si no se le echa cloro, se convierte en un vehículo de transmisión de enfermedades contagiosas. Los peces se mueren en los ríos y empiezan a desaparecer de muchas costas. Se comienza a hablar de la contaminación térmica. La liberación de energía térmica a través de la industria y sus desechos empieza a poner en peligro el equilibrio ecológico. Todo esto es tema frecuente en la Prensa y en las revistas, no sólo especializadas, sino en las que se dirigen al gran público.

Al lado de esta corriente existe otra más modesta, no porque afecte a menos personas, sino porque tiene menos cauces de expresión. Algunos representantes de países subdesarrollados en la Conferencia de Estocolmo dijeron que en su patria el aire es bas. tante limpio, que a ellos lo que les pasa es que tienen hambre. Detrás de esta queja vienen otras sobre la distribución mundial de la riqueza y algunas de sus causas: el modo de funcionar el comercio internacional, el sistema monetario y crediticio. Hay una contaminación que no se percibe por los sentidos, pero que afecta profundamente al hombre y puede hacerle intensamente desgra. ciado. Por darle algún nombre, podríamos llamarla contaminación moral. 
La contaminación del medio ambiente-la de los humos y las aguas la conocemos y la medimos científicamente, pero también la percibe el hombre vulgar inmediatamente, aunque sin el rigor de los estudios científicos. Notamos por el olfato que estamos respirando azufre, y por el sabor, que estamos bebiendo una solución de cloro. La contaminación moral no ha sido estudiada cientificamente en la mayor parte de sus manifestaciones, pero la percibimos inmediatamente todos los días.

En su puesto de trabajo-que es donde pasa la parte más importante del día-, el hombre corriente se tropieza fácilmente con la adulación, la envidia, la arbitrariedad, el egoísmo y la desho. nestidad. Si uno quiere comprar algo, tiene que tener culdado de que no le engañen. La criminalidad y el gamberrismo se van convirtiendo en algo más frecuente y de experiencia más inmediata. Ya no son cosas que únicamente se leen en los periódicos y que les pasan a seres desconocidos.

Si uno quiere distraerse leyendo un libro o asistiendo a un espectáculo, cada vez es más difícil elegir. Se ha puesto de moda el antihéroe. Se glorifica al hombre lujurioso, agresivo, cobarde, alcohólico y psicópata. Las noticias de la Prensa son de matanzas, escándalos políticos y financieros y cosas por el estilo. Hay una serie de síntomas que nos pueden inducir a pensar que hay una escalada de inmoralidad. Es muy loable la preocupación por la calidad de la vida de que hacen gala los estudiosos de la contaminación. pero ¿no sería necesario ampliar el abanico de los contaminantes?

\section{La escalada de la inmoralidad}

Dentro del campo de la contaminación moral merece una atención especial todo lo que se refiere a la injusticia social o-si se prefiere-, para darle una mayor amplitud, a la inmoralidad social. No sólo porque hay una mayor sensibilidad en el hombre de hoy a las injusticias sociales, sino porque, al ser más universales, afectan y dañan más extensamente a los hombres. Las hay que son de carácter estructural. Pensemos en horarios y condiciones de trabajo, retribuciones, etc.

Hay sistemas que cristalizan una injusta distribución del poder de consumo y del poder de decisión. De estos problemas nos hemos ocupado en otras ocasiones y nos seguiremos ocupando en el futuro. Hay también inmoralidades que no se explican por la deficiencia de las estructuras sociales o económicas y que se acercan más al bandidaje. Aun dentro de unas estructuras deficientes, es distinto el comportamiento del hombre recto y el del hombre deshonesto. La experiencia vivida parece indicar que la proporción de estos últimos aumenta en nuestra sociedad. 
Naturalmente, no tenemos estadísticas sobre este punto, pero la experiencia vivida por los que tienen que relacionarse con el mundo de los negocios parece apuntar hacia una escalada de la inmoralidad. Este fenómeno es bastante universal y no respeta fronteras ni sistemas políticos. Sé de una empresa alemana que proyecta construir una casa de reposo para ejecutivos cansados en una zona turística española. Ese cansancio será debido a sus muchas preocupaciones, pero ¿cuántas de esas preocupaciones serán debidas a la lucha cotidiana con la delincuencia de guante blanco?

Muchos de los lectores conocerán casos más o menos importantes, según el puesto que ocupen, de estas lacras morales. Algunos son de conocimiento público; la mayoría, no. Puede ser útil ilustrar lo dicho con algunos casos concretos. Henri Jannes ha publicado un libro llamado "Le dossier secret du téléphone", sobre el escándalo de los teléfonos franceses. Alto funcionario de la Administración francesa, tiene un conocimiento de primera mano, porque fue uno de los protagonistas del "affaire "-su informe fue considerado como prueba concluyente por la Comisión de Finanzas del Senado-. También ha publicado un artículo en el número de enero de 1973 en la revista Esprit, titulado "Les mécanismes de la corruption", en el que refiere otros casos parecidos, hasta un total de ocho.

El caso de los teléfonos franceses se puede resumir así:

El Ministerio de Correos, Telégrafos y Teléfonos (P.T.T.) tenía dos baremos de precios para pagar a sus proveedores de material telefónico, uno que aplicaba los precios del mercado, y otro, con aumentos de precios que oscilaban de un 200 a un 700 por 100 , que se adjudicaba a las empresas "amigas". La justificación de estos precios se encontraba en un cálculo que aplicaba un coeficiente de revalorización, para tener en cuenta el coste de vida, pero que no tenía en cuenta los aumentos de productividad y la consiguiente disminución de los costes de producción.

Un joven funcionario denunció el caso a sus superiores. No se le hizo caso y, por intervención personal del Ministro de P.T.T., se le retrasó el ascenso. El señor Jannes envió al señor Guéna -a los ocho días de su toma de posesión como Ministro de P.T.T.un informe sobre el escándalo de los teléfonos. Henri Jannes cuenta que estuvo veinte meses a las órdenes del Ministro Guéna y que en todo ese tiempo no le recibió para tratar de este asunto. Escribió al Presidente de la Confederación de Patronos Franceses, avisándole de que, como consecuencia del escándalo de los teléfonos, las empresas privadas francesas habían tenido que pagar de más unos 350.000 millones de francos antiguos (más de 35.000 millones de pesetas). No obtuvo respuesta. Añade Jannes que el Vicepresidente de dicha Confederación era el Director General 
de la C.G.E., una de las empresas beneficiarias de los hechos denunciados. El señor Jannes se dirigió después al Presidente Pompidou, a quien envió el "dossier" del asunto de los teléfonos, sin ningún resultado. Finalmente, la Comisión de Finanzas del Senado tomó en cuenta la denuncia del señor Jannes, y en su informe dice: " $M$. Jannes, ingeniero general de las telecomunicaciones, puso en evidencia, en documentos públicos fundamentales, un error de evaluación del simple al décuplo, lo que ha tenido y tiene todavía como consecuencia dar una apariencia de legitimidad a procedimientos que hacen perder al Estado por lo menos 1.000 millones de francos nuevos al año" (...) "los datos no pueden ser discutidos ni lo han sido nunca".

Más adelante, dice el informe que estos abusos han durado durante los cinco años del V Plan, de modo que las pérdidas pueden ser evaluadas en 5.000 millones de francos nuevos (más de 50.000 millones de pesetas). Añade Henri Jannes que el funcionavio directamente responsable del "golpe" de los dos baremos ha sido ascendido y puesto al frente de un departamento que controla el empleo de unos 700.000 millones de francos antiguos (unos 70.000 millones de pesetas). El Secretario de la comisión del V Plan que elaboró las inversiones telefónicas, alto funcionario de Teléfonos, ha pasado a ser Director General de la Ericsson, una de las principales beneficiadas por el "affaire" de los teléfonos. El mismo Henri Jannes, aparte de las muchas amenazas recibidas, ha sido procesado dos veces, una por falso testimonio, la otra por difamación de un miembro del Gobierno. Las dos veces fue declarado inocente.

El señor Galley, Ministro de P.T.T. durante el tiempo del "affaire" arriba descrito, se vio también implicado en otro asunto poco claro. Un promotor quiso construir una gran urbanización en la isla de Ré. El proyecto recibió la conformidad de las autoridades municipales y departamentales. El promotor ve aparecer, de la noche a la mañana, una sociedad "sin fin lucrativo", formada por diez miembros. El Presidente es el señor Dechartre, Secretario de Estado para Asuntos Sociales; el Vicepresidente es el señor Galley, Ministro de P.T.T. Esta asociación, según numerosos testigos, reclamó al promotor 500 millones de francos, sin los cuales su proyecto sería rechazado. Como consecuencia de este "affaire", el señor Dechartre tuvo que abandonar el Gobierno, pero el señor Galley continuó como Ministro.

Los otros casos que cuenta Henri Jannes son parecidos, aunque no alcanzan el volumen del de los teléfonos. Podemos añadir, para terminar, que hablando Henri Jannes de su libro con un alto funcionario del Ministerio de Obras Públicas francés, éste le dijo que él podría escribir otro libro parecido sobre las obras públicas, pero que no lo hacía porque tenía tres hijos. 
Si he traído aquí estos casos es únicamente por la razón de que Henri Jannes los ha hecho públicos bajo su propia responsabilidad. No hay ninguna razón que nos induzca a pensar que hay más inmoralidad en Francia que en otros países, ni que hay más inmoralidad en la administración pública que en la administración privada.

\section{Un Club de moralistas}

El Club de Roma es una asociación informal internacional, fundada en abril de 1968 por el Dr. Aurelio Peccei y treinta miembros de diez países. Actualmente son unas setenta personas de veinticinco países. Su fin es promover la comprensión de los variados componentes interdependientes-económicos, políticos, naturales y sociales-que componen el sistema global en que vivimos; llamar la atención de los políticos y de la opinión pública, y promover nuevas iniciativas y acciones políticas.

El Club de Roma se ha propuesto elaborar un proyecto sobre la peligrosa situación de la Humanidad. Intenta examinar un conjunto de problemas que turban a los hombres de todas las nacio. nes. Estos problemas son ocho: 1. Pobreza en medio de la abundancia. 2. Degradación del medio ambiente. 3. Pérdida de fe en las instituciones. 4. Expansión urbana incontrolada. 5. Inseguridad de empleo. 6. Enajenación de la juventud. 7. Rechazo de valores tradicionales. 8. Inflación y otros desequilibrios monetarios y económicos.

A su juicio, estos son los problemas más importantes que tiene planteados la Humanidad. Unos son materiales, otros morales y otros mixtos. Una primera fase de este proyecto tan ambicioso la constituye el estudio de un modelo limitado, realizado por un equipo de investigadores del instituto de Tecnología de Massachusetts, dirigido por Dennis Meadows.

El profesor del M.I.T. Jay Forrester, pionero en el campo de "System dynamics" y miembro del Club de Roma, presentó un modelo global que permite la identificación de algunos componentes específicos de la problemática, y sugirió una técnica para analizar el comportamiento y las relaciones de los diversos factores. La sugerencia fue aceptada por el Club de Roma y financiada por la Fundación Volkswagen. Así nació la investigación de D. Meadows y su equipo y el informe publicado con el título de whe limits of growth". Este informe analiza cinco factores básicos: 1. POblación. 2. Producción agrícola. 3. Recursos naturales. 4. Producción industrial. 5. Contaminación. ¿Por qué eligieron estos factores? Los principales problemas de la Humanidad-a nuestro juicio-quedan excluidos del modelo. No tienen más justificación que 
el que estos factores son los más fácilmente observables y cuantificables y pueden ser procesados por computadoras electrónicas.

No voy a hacer una crítica fácil del "crecimiento limitado". Los mismos investigadores del M.I.T. son conscientes de la limitación de sus resultados y no toman muy en serio la profecía de sus cerebros electrónicos de que el fin de la Humanidad será hacia el año 2015. La crítica más seria que se les puede hacer es que han sacrificado la autenticidad al método. Por otra parte, el considerar el crecimiento demográfico como problema central de la Humanidad es completamente gratuito. Es un problema importante, pero no es el centro de gravitación de los demás pro. blemas. La principal aportación del informe del M.I.T. es la naturaleza exponencial del crecimiento de dichos factores.

\section{Crecimiento exponencial}

¿Por qué no introducir una nueva variable en el modelo del M. I.T.? La degradación moral o contaminación moral, o como se la quiera llamar, es tan importante por lo menos como el agotamiento de los recursos naturales o la contaminación ambiental. Se podrá objetar inmediatamente que no hay un acuerdo entre los hombres sobre una escala de valores morales y que estos mismos valores no son mensurables, porque pertenecen a lo más intimo de la persona y no se puede juzgar a nadie por las apariencias. La objeción es válida si pretendiéramos construir un modelo matemático ampliado. Pero podemos aplicar a la contaminación algunos principios fundamentales del modelo del M.I.T. utilizando nuestros propios cerebros en vez de los cerebros electrónicos. Hay algunos valores morales universalmente admitidos, y podemos $\mathrm{li}$ mitar a ellos nuestro análisis.

Según el informe Meadows, un factor crece exponencialmente cuando en su crecimiento se dan espirales de realimentación ("feedback loops"). Si encontramos que la contaminación moral crece y que en este crecimiento se dan "feedback loops", podremos concluir que la contaminación moral crece exponencialmente, aunque ignoremos su índice de crecimiento. También podemos relacionar la contaminación moral con los otros factores del modelo y averiguar en qué sentido se influyen mutuamente, aunque desconozcamos la proporción.

Que la inmoralidad crece lo sabemos positivamente en algunos casos. El índice de criminalidad crece en casi todos los países. La distancia entre la minoría opulenta y la mayoría subdesarrollada crece a nivel mundial, según todos los estudios realizados por los expertos en desarrollo. 
Tomando como punto de referencia las relaciones de la inmoralidad con la riqueza y la pobreza, encontramos los siguientes "feedback loops":

La riqueza produce contaminación moral. No queremos decir que todos los ricos son inmorales. Ahora no consideramos otro factor que se podría introducir en el modelo, que sería la bondad o rectitud moral y del cual tendremos que decir algo más adelante. En muchos casos, la riqueza produce contaminación moral. Podemos considerar el aumento de corrupción administrativa y de corrupción en la vida de los negocios, del que hemos puesto algunos ejemplos más arriba, que lleva consigo el desarrollo. Ahora bien, la contaminación moral produce más riqueza. Esto es evidente a nivel individual. Los hombres de negocios sin escrúpulos morales y los administradores corrompidos se enriquecen rapidísimamente. Lo mismo ocurre a nivel colectivo. El crecimiento espectacular de las grandes empresas con dirigentes inmorales produce un aumento de la riqueza nacional como efecto secundario (nuevas inversiones, nuevos puestos de trabajo). El aumento de riqueza produce nuevo aumento de la contaminación moral, y así sucesivamente. Tenemos una perfecta espiral de realimentación.

La pobreza produce contaminación moral. No nos referimos a la pobreza como actitud espiritual, sino a la pobreza como situación existencial, que en muchos casos produce degradación moral. El pobre busca muchas veces su consuelo en el vino. Los barrios más pobres son los que tienen un mayor índice de criminalidad. También socialmente la pobreza produce contaminación moral.

Los países subdesarrollados producen su propia especie de corrupción, con características diferentes que la de los desarrollados y no tan refinada. Crímenes políticos y explotación de los débiles son moneda corriente en los países subdesarrollados. Esta contaminación moral produce más pobreza. A nivel individual, el hombre abandonado y vicioso termina perdiendo el empleo o dilapidando su escaso patrimonio. A nivel social, los frutos de la corrupción se dirigen principalmente hacia gastos suntuarios y se procura mantener el "status" vigente, que entorpece las posibilidades de desarrollo. Es el círculo vicioso del subdesarrollo. Tenemos un auténtico "feedback loop".

Podemos perfeccionar nuestro análisis introduciendo un elemento dinámico. Hay pueblos que rompen el círculo de hierro del subdesarrollo. Pero entonces crece más de prisa la riqueza de los ricos y la pobreza de los pobres. No quiere decir que tengan menos cosas que antes, sino que es mayor la diferencia. Los pobres de ahora tiene más cosas que los pobres de hace un siglo, pero sus apetencias han crecido más de prisa todavía que sus satisfacciones. Cuando se alcanza un alto grado de desarrollo, apa- 
rentemente disminuyen las diferencias, pero en realidad to que ocurre es que se transfiere la pobreza a otros países menos afortunados. Los países ricos se hacen más ricos y los países pobres se hacen más pobres.

Nos queda por analizar cómo influye la contaminación moral en los otros factores del modelo del M. I.T.

1. La contaminación moral produce un aumento de la producción industrial, especialmente de cosas inútiles. La ambición desmedida lleva a producir más cosas, sin atención a las verdaderas necesidades sociales. Se induce a la gente a comprar más para poder producir más y vender más para producir más... Al rendimiento máximo corresponde la inmoralidad máxima. La voluntad de dominio y el espíritu de violencia llevan a una escalada de la producción de armamentos, que es lo más caro y lo más inútil que existe. Lo mejor que se puede desear de los formidables y carísimos arsenales de las grandes potencias es que nunca sirvan para nada.

2. La contaminación moral produce una disminución de la producción de alimentos. Cuando se rompe la barrera del desarrollo, suele ser a costa de los agricultores. Una vez alcanzado un alto grado de desarrollo, se suelen alcanzar altos niveles de producción de alimentos en los países desarrollados, pero con una política proteccionista y altamente discriminadora contra los países subdesarrollados. En los países subdesarrollados, la producción de alimentos es postergada en favor del cultivo de plantas industriales y de productos coloniales para la exportación. El balance mundial es que la población crece más de prisa que la producción de alimentos. Aquí es necesario hacer una referencia al factor no considerado de la bondad o rectitud moral, que produce el efecto contrario y hace que sea menos notable el efecto de la contaminación moral.

3. La contaminación moral produce un despilfarro en la utilización de los recursos naturales. El egoísmo lleva a una falta de consideración hacia las generaciones futuras o hacia las necesidades de otros pueblos, para conseguir unas mayores ganancias inmediatas.

4. La inmoralidad produce un aumento de la contaminación ambiental, por las mismas razones que en el caso anterior.

$5 .^{\circ}$ En lo relativo al crecimiento demográfico, la contaminación moral influye en dos direcciones distintas. En los países desarrollados lleva a una disminución de dicho crecimiento. El egoísmo lleva a disminuir cada vez más el número de hijos por todos los procedimientos, incluido el aborto en gran escala. En los países subdesarrollados, la contaminación moral lleva a un crecimiento 
demográfico. Los programas de control de natalidad, promovidos y financiados por los países desarrollados, no producen un efecto sensible en la tasa de crecimiento de la población en los países subdesarrollados. El control de natalidad sólo se ha mostrado eficaz cuando se ha alcanzado un determinado nivel de desarrollo. Entre los subdesarrollados, la obsesión erótica se traduce en un aumento de los nacimientos. Como en el conjunto de la población mundial son más los subdesarrollados que los desarrollados, podemos concluir que la contaminación moral hace aumentar el crecimiento demográfico, pero creciendo más de prisa el número de pobres que el de ricos.

\section{El reverso de la medalla}

La contaminación moral crece exponencialmente. En cualquier momento puede dispararse hacia arriba-que es lo típico de toda función exponencial-, si es que no lo ha hecho ya. Su influjo en los problemas de la Humanidad es el de empeorarlos. Si los investigadores del M.I.T. hubieran introducido esta variable en su modelo, hubieran tenido que adelantar la fecha del fin de la Humanidad. Sin embargo, esta conclusión hubiera sido tan falsa como la otra. Ha quedado fuera otro factor importantísimo: la bondad humana. Este factor crece y también de una manera exponencial. Si comparamos nuestros sistemas procesales y penales con los de hace doscientos años, es evidente que hemos progresado en sentido de justicia y de equidad. La situación de los obreros ha mejorado considerablemente en muchos países, que en el siglo XIX presentaban un espectáculo lamentable de explotación y miseria junto a la riqueza de unos pocos. Con ocasión de grandes catástrofes, como terremotos, inundaciones, etc., hemos visto una oleada de generosidad y sacrificio para ayudar a los hermanos en desgracia.

Siguiendo el método del M.I.T., podemos encontrar los "feedback loops" que nos demuestren que la rectitud moral crece exponencialmente:

Un aumento en la producción de alimentos produce más bondad en los hombres. El hombre liberado de la esclavitud del hambre encuentra más fácil la práctica de la virtud. Esta es una verdad muy antigua, de la que ya hizo mención Santo Tomás en la "Summa Theologica" y que recogió León XIII en la "Rerum Novarum". La bondad lleva a aumentar la producción de alimentos. Cuando se concedió el premio Nobel de la Paz al principal promotor de la "revolución verde", no se premiaban unos méritos científicos, que existían, sino una acción humanitaria, es decir, la bondad y rec. titud de un hombre. Ya tenemos una espiral en marcha. 
Relacionando la bondad moral con otros factores del modelo del M.I.T., encontramos nuevos "feedback loops" y, al mismo tiempo, podemos observar por dónde irían las interrelaciones de un modelo ampliado. Un crecimiento de la bondad moral lleva a un crecimiento en la economía de recursos naturales, a orientar la producción hacia bienes socialmente útiles, a concentrar el esfuerzo humano en la producción de servicios útiles al hombre, como la educación. Estos resultados vuelven a engendrar más bondad. Un ambiente en el que domina el interés social sobre el interés privado, una educación esmerada, son los mejores productores de hombres buenos y honrados.

La bondad produce también menos contaminación. No sólo porque no es egoísta, sino porque el hombre bueno es amante de la Naturaleza, de los animales y de las plantas; no destruye gratuitamente la vida. A su vez, un descenso en la contaminación favorece el que los hombres sean mejores. Los urbanistas y los psicólogos saben que hay una relación de la criminalidad y de la agresividad con un medio urbano inhumano, por su aglomeración, por los humos, ruidos y otros factores contaminantes.

\section{El fin de Prometeo}

Para que el modelo del M.I.T. sea verdaderamente significan tivo hay que ampliarlo con estas dos variables: la contaminación moral y la bondad o rectitud moral. Las dos crecen exponencialmente y las dos influyen de una manera decisiva en los otros factores, pero no conocemos sus índices de crecimiento ni sabemos cuál crece más de prisa. Probablemente, los cerebros electrónicos no nos lo podrán decir nunca. Con esto lo que hemos hecho es volver loco al modelo. Ya no podemos saber nada científicamente válido sobre el futuro de la Humanidad. Quizá esto no sea un mal. Nos puede servir para destruir un complejo de Prometeo. Según Edgar Morin, éste es uno de los defectos de la civilización occidental, tanto de la burguesa como de la marxista. Conciben a un hombre conquistador de la Naturaleza, que acaba siendo un Gengis Khan del entorno solar. Tenemos que aprender a vivir con la incertidumbre del futuro. Al fin y al cabo ésta es la condición de cada hombre particular. Ignoramos lo que será de nosotros; sólo sabemos que al final está la muerte. Para el creyente hay un horizonte más atrayente, porque sabe que su muerte no será ni absoluta ni definitiva. Esta esperanza da un sentido a su vida y hace la justicia deseable por sí misma, aunque quede envuelto en la oscuridad hasta qué punto lo va a conseguir y cómo va a influir en el modelo global de la problemática inmanente de la Humanidad. Quizá se pueda decir que el "crecimiento limitado" es un maravilloso juego científico o, usando imágenes bíblicas, una versión moderna y cibernética de la Torre de Babel. 